\title{
The Ethyl Acetate Extract of Gynura formosana Kitam. Leaves Inhibited Cervical Cancer Cell Proliferation via Induction of Autophagy
}

\author{
Jing Fan Ma $\mathbb{D}^{1,2,3}$ Peng Fei Wei, ${ }^{4}$ Chang Guo, ${ }^{1,2,3}$ Yuan Peng Shi, \\ Yang Lv, ${ }^{1}$ Long Xin Qiu $\mathbb{1},^{1,2,3}$ and Long Ping Wen $\mathbb{D}^{1,4}$ \\ ${ }^{1}$ Department of Biological Science and Technology, School of Life Sciences, Longyan University, Longyan University, China \\ ${ }^{2}$ Key Laboratory of Preventive Veterinary Medicine and Biotechnology (Longyan University), Fujian Province University, \\ Longyan, China \\ ${ }^{3}$ Fujian Provincial Key Laboratory for the Prevention and Control of Animal Infectious Diseases and Biotechnology, \\ Longyan University, Longyan, Fujian 364012, China \\ ${ }^{4}$ Hefei National Laboratory for Physical Sciences at the Microscale, School of Life Sciences, \\ University of Science and Technology of China, Hefei, Anhui 230027, China
}

Correspondence should be addressed to Long Xin Qiu; 1923015106@qq.com and Long Ping Wen; lpwen@ustc.edu.cn

Received 22 November 2017; Revised 16 March 2018; Accepted 2 April 2018; Published 24 May 2018

Academic Editor: Gang Liu

Copyright (C) 2018 Jing Fan Ma et al. This is an open access article distributed under the Creative Commons Attribution License, which permits unrestricted use, distribution, and reproduction in any medium, provided the original work is properly cited.

Gynura formosana Kitam. belongs to the Compositae family and has been traditionally used for the prevention of cancer, diabetes, and inflammation in China. Previous studies had indicated that the ethyl acetate extract of Gynura formosana Kitam. leaves (EAEG) exhibited antioxidant and anti-inflammatory activity. In this report, we demonstrated that EAEG possessed potent anticancer activity through autophagy-mediated inhibition of cell proliferation. EAEG induced a strong cytostatic effect towards HeLa cells and, to a lesser extent, HepG2 and MCF-7 cells. This cytostatic effect of EAEG was not a consequence of increased apoptosis, as neither DNA fragmentation nor change in protein expression level for a number of apoptosis-related genes including Bid, Bax, Bcl2, and caspase-3 was observed after EAEG treatment, and the apoptosis inhibitor Z-VAD-FMK did not inhibit the EAEG-elicited cytostatic effect. On the other hand, EAEG induced autophagy in a dose-dependent fashion, as shown by increased GFP puncta formation, enhanced conversion of the microtubule-associated protein light chain LC3-I to LC3-II, and downregulation of the p62 protein. Treating the HeLa cells with EAEG together with Chloroquine (CQ) further accelerated LC3 conversion and p62 clearance, indicating that EAEG induced complete autophagy flux. Importantly, the autophagy inhibitor 3-methyladenine (3MA) significantly abrogated the cytostatic effect of EAEG, strongly suggesting that EAEG inhibited HeLa cell proliferation through the induction of autophagy rather than apoptosis. Our results provided a novel and interesting mechanistic insight into the anticancer action of EAEG, supporting the traditional use of this plant for the treatment of the cancer.

\section{Introduction}

Cervical cancer is the second most common malignant tumor and the fourth main cause of cancer deaths in women worldwide [1,2]. Over half a million cases are diagnosed every year, with the mortality rate of $9 \%$ in the world. In China, 130,000 cases are diagnosed with cervical cancer each year and account for $28 \%$ of new cases globally. The mortality rate is $14 \%$, which is higher than that in other developing countries $[3,4]$. Cervical cancer could be traditionally treated with surgery and chemoradiotherapy. However, anticancer drugs of such approach are highly toxic. Therefore, the development of new anticancer drugs with fewer side effects is very necessary. Plant-derived bioactive compounds are important resources for treating various forms of the cancer [5]. Numerous studies have demonstrated that plant extracts had antiproliferative or antitumor effects on tumor cells [68]. 
Gynura formosana Kitam. (family Compositae) is a frequently used vegetable in China. It exhibited various biological activities and had been used for the prevention of cancer, diabetes, and inflammation in the Chinese traditional system of medicine since ancient times. The leaves of Gynura formosana Kitam. contained several medicinally relevant components such as polyphenolics, flavonoids, alkaloids, terpenes, and saponins [9]. These substances might contribute to its biological activity. Our previous studies had exhibited that the ethyl acetate extract of Gynura formosana Kitam. leaves (EAEG) had high quantity of polyphenolics and flavonoids and had antioxidant and anti-inflammatory effects [9]. Recent studies showed that several bioactive compounds extracted from plants, mostly polyphenolics and flavonoids, played an important role in tumor cells inhibition effect $[10,11]$. Distinctly, EAEG, a polyphenolic- and flavonoid-rich extract, is potentially relevant for preventing and treating tumor cells. However, the anticancer effect of EAEG was rarely reported. Therefore, in the present study, we investigated the effect of EAEG on the proliferation of human tumor cells and its underlying mechanism.

Autophagy, as a cellular self-digestive process, is also considered an evolutionarily conserved and lysosome-dependent process in all mammalian cells, which is associated with cell survival. It helps cells obtain nutrients under deprivation conditions. However, more and more studies [12] have shown that, despite its importance in maintaining cell homeostasis, autophagy plays also a vital role in the regulation of cell death. Actually, continuous "autophagy" will commit suicide. So autophagy may play a protective role against cancer

\section{Materials and Methods}

2.1. Reagents. All of cell culture reagents were purchased from HyClone Laboratories (Logan, UT, USA). Trehalose (Tre), Z-VAD-FMK, 3-methyladenine (3MA), and Chloroquine (CQ) were purchased from Sigma-Aldrich (St. Louis, MO, USA). LC3 antibody was purchased from Novus (Littleton, CO, USA) and glyceraldehyde phosphate dehydrogenase $(\mathrm{GAPDH})$ antibody from Millipore. Bid, Bax, and Bcl-2 antibodies were all obtained from Santa Cruz Biotechnology (Santa Cruz, CA, USA). Caspase-3, p62, PCNA, and MCM7 antibodies were purchased from Cell Signaling Technology (Danvers, MA, USA). $\beta$-Actin antibody was purchased from Sigma Chemical Co. (St. Louis, MO, USA).

2.2. Preparation of EAEG. EAEG was prepared according to our previously published literature [9]. Briefly, $200 \mathrm{~g}$ of Gynura formosana Kitam. leaves powder was firstly soaked in petroleum ether for $24 \mathrm{~h}$ and then the extract was filtered, evaporated at $45^{\circ} \mathrm{C}$, and dried in a freeze-dryer. The residue was extracted successively in chloroform and ethyl acetate in the same way. The yields of petroleum ether, chloroform, and ethyl acetate extracts were $9.9 \%$, $2.3 \%$, and $3.2 \%$, respectively. In our previous studies, EAEG showed the strongest 1,1-diphenyl-2-picrylhydrazyl radical, 2,2-diphenyl-1-(2,4,6-trinitrophenyl)hydrazyl (DPPH) and 2,2' -azino-bis(3-ethylbenzthiazoline-6-sulfonic acid) (ABTS) radical scavenging activities in three extracts. The polyphenol and flavonoid contents in EAEG were $34.12 \pm 0.01 \mathrm{mg} / \mathrm{g}$ gallic acid equivalent and $44.35 \pm 0.02 \mathrm{mg} / \mathrm{g}$ catechin equivalent, respectively [9].

2.3. Cell Culture. HeLa and HepG2 cells were purchased from the American Type Culture Collection (ATCC, Manassas, VA, USA). MCF-7 cells were kindly provided by Professor Longping Wen (University of Science and Technology of China, Hefei, Anhui). HeLa cells stably expressing GFPLC3 were constructed as previously described [13]. All cells were grown in DMEM supplemented with 10\% FBS and 1\% penicillin-streptomycin in a humidified atmosphere of $5 \%$ $\mathrm{CO}_{2}$ at $37^{\circ} \mathrm{C}$.

2.4. Cell Viability Assay. Cell viability was determined by $3-$ (4,5-dimethylthiazol-2-yl)-2,5-diphenyltetrazolium bromide (MTT) assay according to the manufacturer's protocols (Sigma Chemical Co.). In brief, cells were cultured in 96-well flat bottom plates overnight and then treated with different concentrations $(0,15,30,45,60,75,90$, and $105 \mu \mathrm{g} / \mathrm{ml})$ of EAEG. After incubation for 24, 48, or $72 \mathrm{~h}, 100 \mu \mathrm{l} \mathrm{MTT}$ solution $(1 \mathrm{mg} / \mathrm{ml})$ was added to each well and the plates were incubated at $37^{\circ} \mathrm{C}$ for $4 \mathrm{~h}$. The supernatants were then removed and DMSO was added to each well to dissolve the MTT-formazan crystals formed by viable cells. Finally, the absorbance values were determined by a microplate reader (Bio-Rad, Hercules, CA, USA) at a wavelength of $570 \mathrm{~nm}$.

2.5. Detection of DNA Fragmentation by Agarose Gel Electrophoresis. After treatment of HeLa cells with different concentrations $(0,45,60$, and $75 \mu \mathrm{g} / \mathrm{ml})$ of EAEG for 24 or $48 \mathrm{~h}$, the phenol/chloroform/isoamyl alcohol was used to extract DNA from cells that had been digested with proteinase K. Cell lysate was collected, incubated at $55^{\circ} \mathrm{C}$ for $10 \mathrm{~h}$, and then treated with $40 \mu \mathrm{g} / \mu \mathrm{l}$ DNase-free RNase at $37^{\circ} \mathrm{C}$ for $40 \mathrm{~min}$. The DNA was precipitated with 4 volumes of ethanol and electrophoresed in $1.5 \%$ agarose gels and visualized by ethidium bromide staining using a Chemidox (BioRad, Hercules, CA).

2.6. Western Blot. HeLa cells were trypsinized, collected by centrifugation, and homogenized in ice-cold RIPA Lysis Buffer (Beyotime, Haimen, China). Protein concentration was analyzed by Bradford Protein Assay Kit (Beyotime, Haimen, China). $35 \mu \mathrm{g}$ of protein sample was loaded and separated on an SDS/PAGE gel and transferred to PVDF membrane (Millipore, Billerica, MA, USA). The membrane was incubated with Tris-buffered saline containing $0.1 \%$ Tween20 and $5 \%$ nonfat dry milk followed by $2 \mathrm{~h}$ incubation at the room temperature with antibody to Bax, Bid, Bcl-2, caspase-3, $\beta$-actin, GAPDH, p62, and LC3, respectively, and then with horseradish peroxidase-conjugated anti-mouse or anti-goat or anti-rabbit IgG (Sigma, 1:2000). Detection was achieved using enhanced chemiluminescence (ECL) kit (Beyotime, Haimen, China).

2.7. Observation of GFP-LC3 Puncta. HeLa cells stably expressing GFP-LC3 were incubated in 24-well plates and treated with EAEG for $24 \mathrm{~h}$. GFP-LC3 puncta were observed 


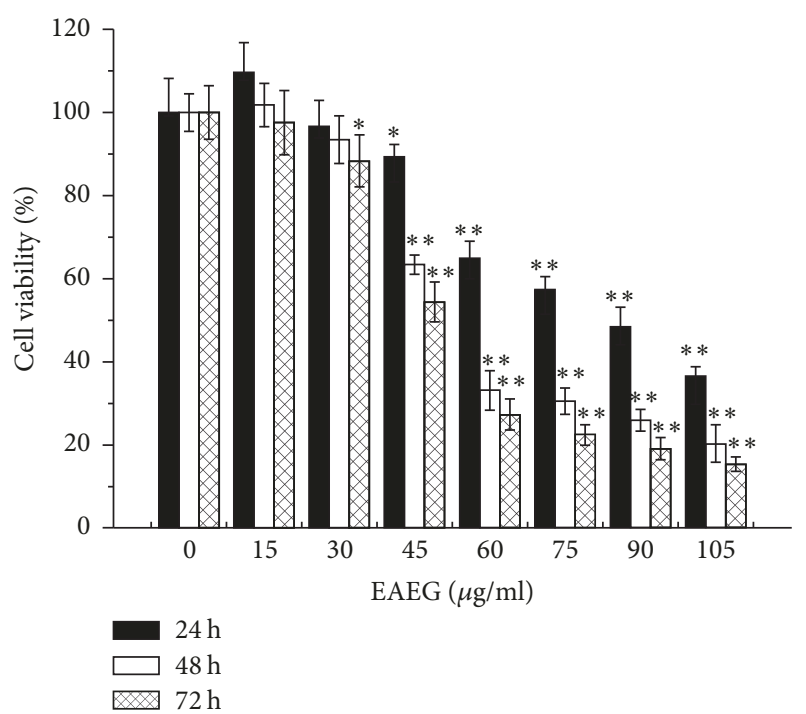

(a)

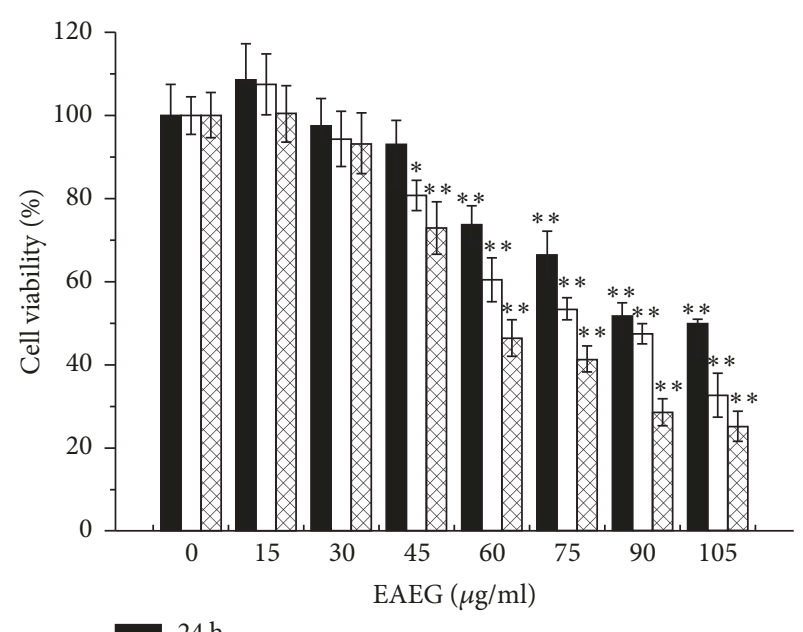

$24 \mathrm{~h}$

(b)

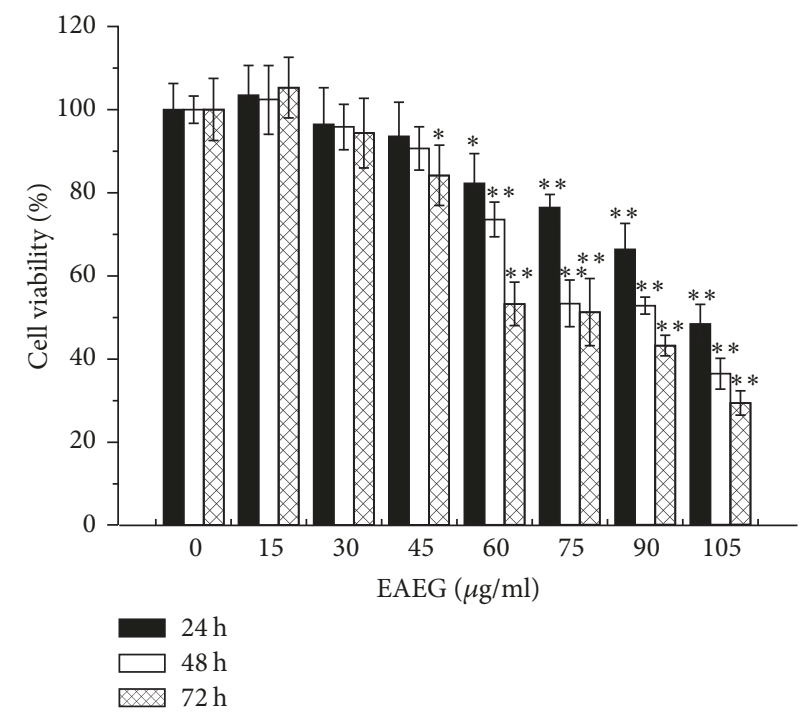

(c)

FIGURE 1: Cell viability comparison of HeLa (a), HepG2 (b), and MCF-7 (c) cells treated with different concentrations of EAEG (0-105 $\mu$ g/ml) for 24,48 , and $72 \mathrm{~h}$. The data were expressed as mean $\pm \operatorname{SEM}(n=6) .{ }^{*} p<0.05$ and ${ }^{* *} p<0.01$ with respect to the control group. EAEG: ethyl acetate extract of Gynura formosana Kitam. leaves.

under fluorescent microscopy (Olympus IX71, Tokyo, Japan). All of photos were captured randomly.

2.8. Statistical Analysis. All of the results were expressed as mean \pm standard error of mean (SEM). Statistical significances were analyzed by one-way analysis of variance (ANOVA) with Dunnett's multiple comparison tests (SPSS version 22.0 software, SPSS Inc., Chicago, IL, USA). $p<0.05$ was considered statistically significant.

\section{Results}

3.1. EAEG Exhibited Cytostatic Effect in Tumor Cells. To investigate the cytostatic effect of EAEG on the tumor cells,
HeLa cells (cervical cancer), HepG2 (liver cancer), and MCF7 cells (breast cancer) were exposed to various concentrations of EAEG for up to 3 days in vitro. As shown in Figure 1, EAEG within a dosage range of $0-105 \mu \mathrm{g} / \mathrm{ml}$ decreased the cell viability in a time- and dose-dependent manner in all three cell lines. Significant $(p<0.05)$ viability-reducing effect was observed at EAEG concentrations of $30 \mu \mathrm{g} / \mathrm{ml}$ and the time of $72 \mathrm{~h}$ in HeLa cells (Figure 1(a)). In comparison, significant decrease of cell viability in HepG2 and MCF-7 cells started at EAEG concentration of $45 \mu \mathrm{g} / \mathrm{ml}$ at the time of $48 \mathrm{~h}$ and $72 \mathrm{~h}$, respectively (Figures $1(\mathrm{~b})$ and $1(\mathrm{c})$ ). Moreover, the $\mathrm{IC}_{50}$ value of EAEG for HeLa, HepG2, and MCF-7 cells was $81.47,100.94$, and $104.76 \mu \mathrm{g} / \mathrm{ml}$ at $24 \mathrm{~h}$, respectively (Figure 1). As $\mathrm{HeLa}$ cells possessed the lowest $\mathrm{IC}_{50}$ value, they were selected for subsequent studies. 
3.2. The Cytostatic Effect of EAEG Was Not due to Enhanced Apoptosis. The most likely explanation for the observed cytostatic effect of EAEG on tumor cells was the induction of apoptotic cell death by EAEG. To investigate this possibility, we conducted DNA fragmentation (the hallmark of apoptotic cell death) assay and also assessed the expression level for a number of apoptosis-related proteins. Treatment of HeLa cells with EAEG at a range of concentrations up to $75 \mu \mathrm{g} / \mathrm{ml}$ for either $24 \mathrm{~h}$ or $48 \mathrm{~h}$ induced no DNA fragmentation (Figure 2(a)) and did not alter the expression level of Bid, Bax, $\mathrm{Bcl}-2$, and caspase-3 (Figures 2(b) and 2(c)). Furthermore, Z-VAD-FMK, an apoptosis inhibitor [14], did not affect the viability-reducing effect of EAEG (Figures 2(d) and 2(e)). Taken together, these results indicated that the cytostatic effect of EAEG in HeLa cells was apoptosis-independent.

3.3. EAEG Induced Complete Autophagy. Autophagy modulation has been demonstrated to be a critical mediator of anticancer efficacy for many drugs [15-17]. Our results above showed that EAEG did not cause apoptotic cell death in HeLa cells, so we next investigated whether EAEG induced autophagy. We used GFP-LC3/HeLa, a cell line stably expressing GFP-LC3, a fusion protein between green fluorescent protein (GFP) and microtubule-associated light chain 3 (LC3), protein. GFP-LC3 protein accumulated to form green fluorescence puncta on autophagosome membranes upon autophagy [13]. Similar to trehalose, the positive control, EAEG at the various concentrations induced significant puncta formation, while DMSO (EAEG solvent) did not, indicating that EAEG elicited autophagy (Figure 3(a)). In addition, EAEG treatment significantly enhanced the conversion of LC3-I to LC3-II and reduced the protein level of p62, a common autophagic substrate, with significant $(p<0.01)$ changes observed at $60 \mu \mathrm{g} / \mathrm{ml}$ and above for $24 \mathrm{~h}$ (Figure 4(a)), lending further proof for the occurrence of autophagy and also suggesting that the autophagy induced by EAEG was complete with normal cargo degradation (Figure 3(b)). To further support the latter conclusion, we treated HeLa cells with $60 \mu \mathrm{g} / \mathrm{ml}$ EAEG for $24 \mathrm{~h}$ in the presence or absence of Chloroquine (CQ), a classical laterstage autophagy inhibitor. Earlier literature showed that the degradation of LC3-II would be impaired in cells treated with saturating dose of CQ $(50 \mathrm{mM})$ [18]. Indeed, a further increase in the level of LC3-II was seen in HeLa cells treated with EAEG plus CQ as compared to HeLa cells treated with EAEG alone (Figure 3(c)), strongly suggesting that EAEG induced complete autophagy with normal flux. As would be expected, p62 degradation was retarded by CQ (Figure 3(c)).

3.4. EAEG Induced Dose- and Time-Dependent Autophagy. To further characterize the autophagic response elicited by EAEG, we performed dose- and time-dependent studies, using LC3-I/LC3-II conversion and p62 protein level as the measures. HeLa cells were treated with different concentrations $(0,40,50,60,70$, and $80 \mu \mathrm{g} / \mathrm{ml})$ of EAEG for $24 \mathrm{~h}$ or with $60 \mu \mathrm{g} / \mathrm{ml}$ EAEG for different times $(0,3,6$, $9,18$, and $24 \mathrm{~h})$. A dose-dependent conversion of LC3-I to LC3-II, accompanied by a corresponding decrease in the level of p62, was observed following EAEG treatment in
HeLa cells, with significant changes observed at $40 \mu \mathrm{g} / \mathrm{ml}$ and above (Figure 4(a)). The conversion of LC3-I to LC3-II and the corresponding decrease in the level of p62 were also time-dependent, with significant change observed at $3 \mathrm{~h}$ and beyond, following EAEG treatment in HeLa cells (Figure $4(\mathrm{~b}))$.

3.5. The Autophagy Induced by EAEG Caused HeLa Cells Death. Did the autophagy induction contribute to the cytostatic effect elicited by EAEG? To assess this possibility, we measured cell viability after the treatment of HeLa cells with EAEG plus 3MA, a class III-PI3K autophagy inhibitor. As shown in Figure 5(a), $60 \mu \mathrm{g} / \mathrm{ml}$ EAEG treatment for $24 \mathrm{~h}$ reduced the cell viability to $64.68 \%$, and this effect was partially offset by the cotreatment with $5 \mathrm{mM} 3 \mathrm{MA}$ (Figure 5(a)), which inhibited significantly the autophagy induced by EAEG (Figure 5(b)). Furthermore, EAEG significantly decreased the level of PCNA and MCM7, two widely used cell proliferation markers [19], and this effect was also partially abrogated by $3 \mathrm{MA}$ (Figure $5(\mathrm{~b})$ ). We thus concluded that EAEG elicited a cytostatic effect on cancer cells through blocking autophagy-mediated cell proliferation rather than inducing apoptosis.

\section{Discussion}

Gynura formosana Kitam. had been used traditionally for the prevention of cancer, diabetes, and inflammation in China. Our previous results showed that EAEG contained polyphenols and flavonoids and had antioxidant and antiinflammatory activities [9]. These collective results suggested that EAEG might present antitumor activity. However, there was little evidence showing the antitumor effects of EAEG.

The plant-derived compounds had served as a main source of drugs, and about more than $50 \%$ of pharmaceuticals were derived from natural compounds [20]. To determine if EAEG could affect the cells proliferation, we first investigated the cytostatic activity of EAEG on HeLa, HepG2, and MCF-7 cells. Our results showed that EAEG reduced the cell viability in time- and dose-dependent manners in three cell lines and was more toxic to HeLa cells (Figure 1), which suggested that EAEG might have better chemotherapeutic potential to cervical cancer. To elucidate the possible mechanism involved in the above cytostatic effects, we assumed that HeLa cells would undergo apoptotic cell death after EAEG treatment. However, any DNA fragmentation could not been detected in HeLa cells treated with even $75 \mu \mathrm{g} / \mathrm{ml}$ EAEG for $48 \mathrm{~h}$. We further investigated the proapoptosis, antiapoptosis, and apoptosis-related proteins expression in HeLa cells treated with EAEG. Bax and Bid were both proapoptotic proteins and could promote apoptotic proteins release. However, the antiapoptotic protein $\mathrm{Bcl}-2$ induced by various pathologic and physiologic stimuli could suppress apoptotic proteins efflux [21-23]. Caspase was a sensitive indicator of apoptosis [24]. We evidenced, in this study, that EAEG could not induce the activation of Bax, Bid, Bcl-2, and caspase- 3 in HeLa cells by Western blot analysis, suggesting that apoptotic pathway was not triggered by EAEG treatment. Most importantly, the 


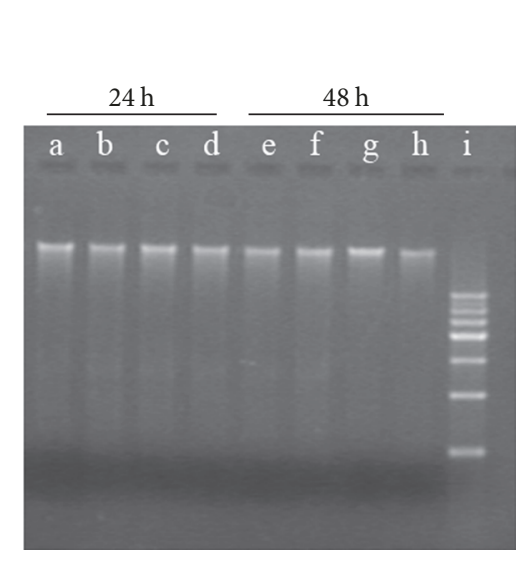

(a)
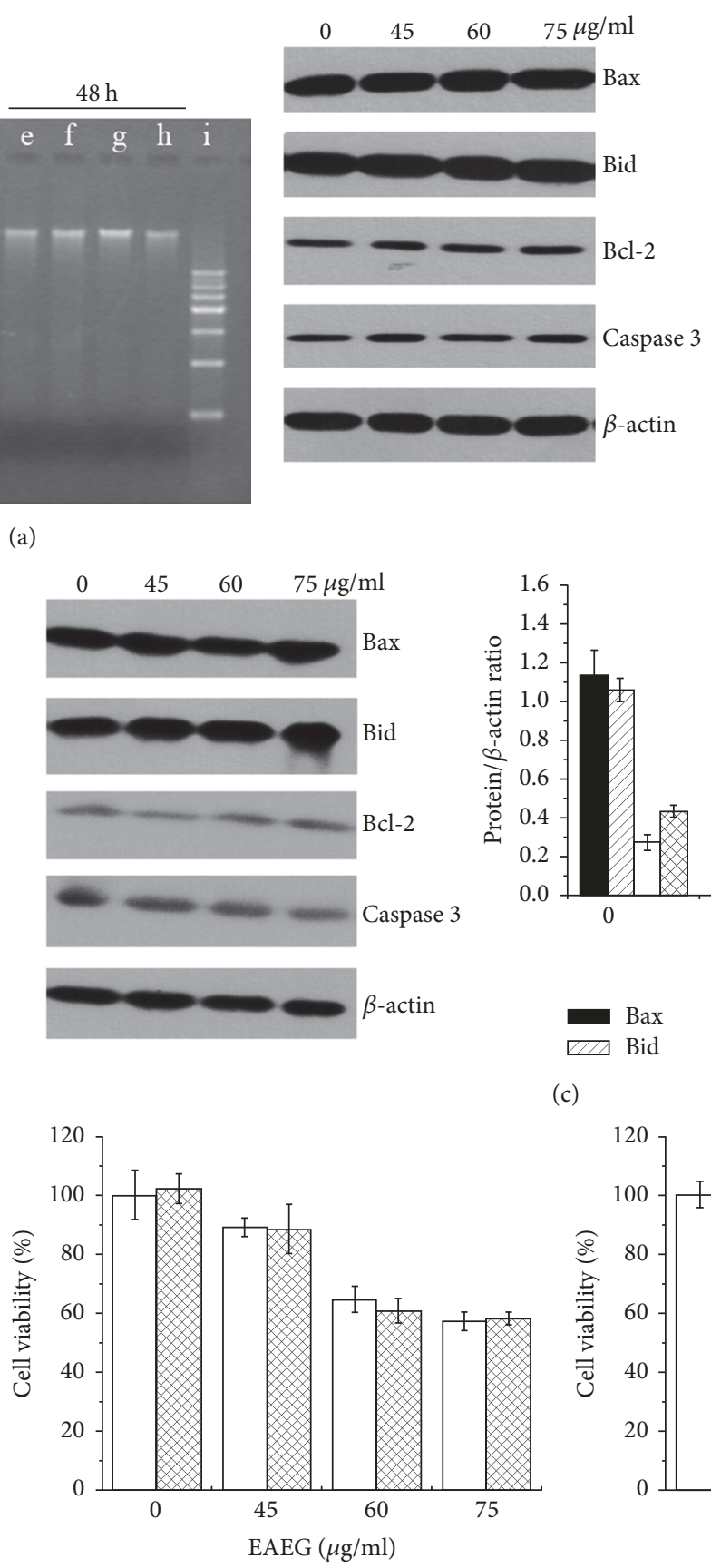

Control

Zvad.fmk $(50 \mu \mathrm{M})$

(d)

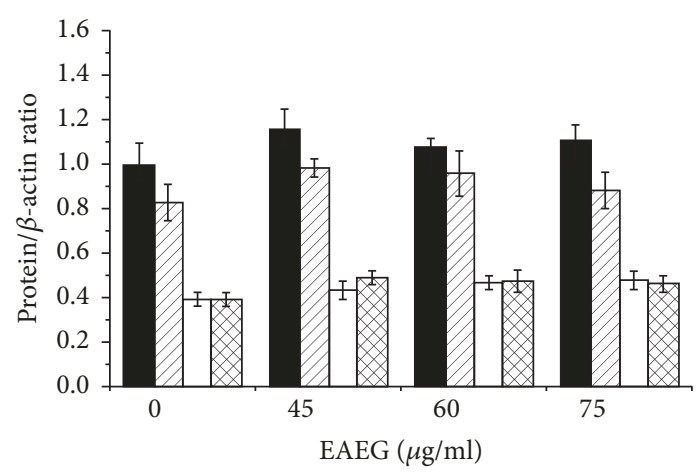

Bax

$\square \mathrm{Bcl}-2$

$\square \times$ Caspase 3

(b)
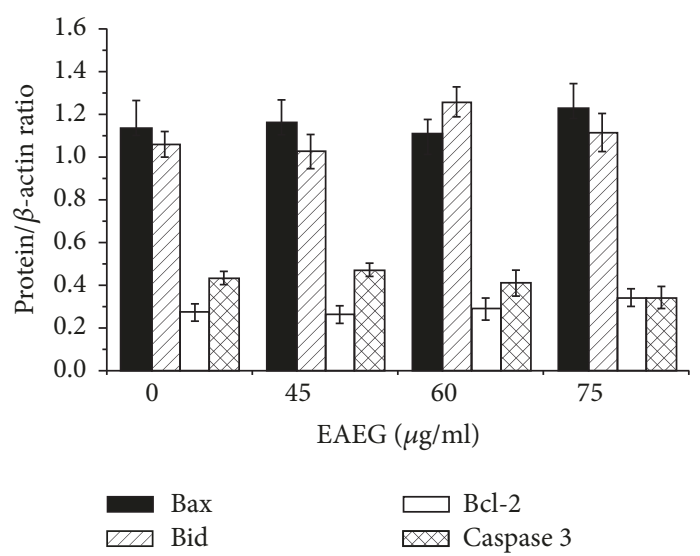

(c)

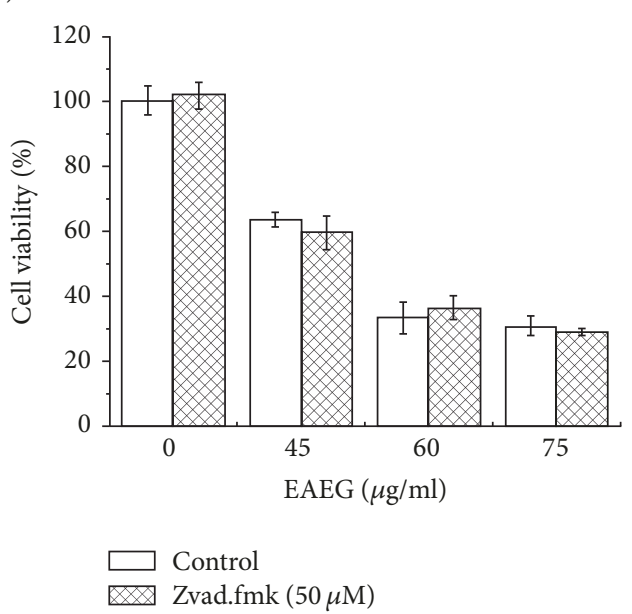

(e)

FiguRE 2: EAEG treatment did not induce apoptotic cell death in HeLa cells. (a) DNA fragmentation analysis. Lines a and e, controls treated for 24 and $48 \mathrm{~h}$, respectively; lines b and f, $45 \mu \mathrm{g} / \mathrm{ml} \mathrm{EAEG} \mathrm{treated} \mathrm{for} 24$ and $48 \mathrm{~h}$, respectively; lines c and g, $60 \mu \mathrm{g} / \mathrm{ml} \mathrm{EAEG} \mathrm{treated} \mathrm{for} 24$ and $48 \mathrm{~h}$, respectively; lines $\mathrm{d}$ and $\mathrm{h}, 75 \mu \mathrm{g} / \mathrm{ml}$ EAEG treated for 24 and $48 \mathrm{~h}$, respectively; line i, DNA marker. ((b) and (c)) The expression of

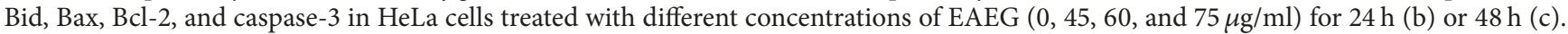
$\beta$-Actin served as the loading control. The relative protein/ $\beta$-actin ratios were calculated using ImageJ. ((d) and (e)) Cell viability of HeLa cells treated with/without Z-VAD-FMK $(50 \mu \mathrm{M})$ and different concentrations of EAEG for $24 \mathrm{~h}(\mathrm{~d})$ or $48 \mathrm{~h}(\mathrm{e})$. The data were expressed as mean $\pm \operatorname{SEM}(n=3)$. EAEG: ethyl acetate extract of Gynura formosana Kitam. leaves. 


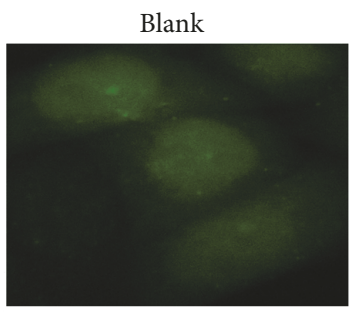

$\operatorname{EAEG}(60 \mu \mathrm{g} / \mathrm{ml})$
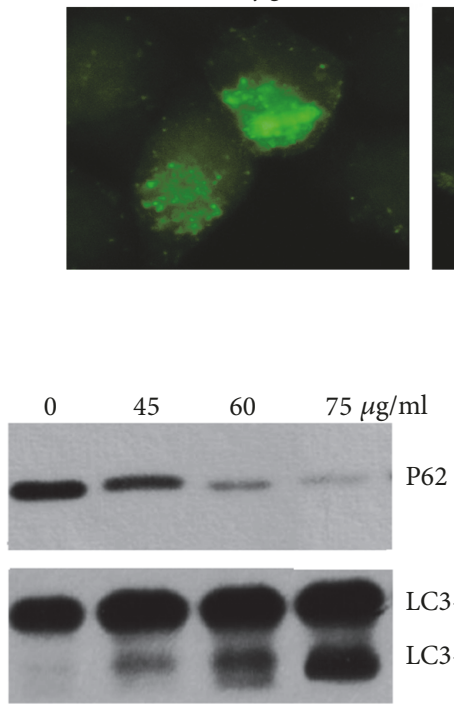

LC3-I

LC3-II
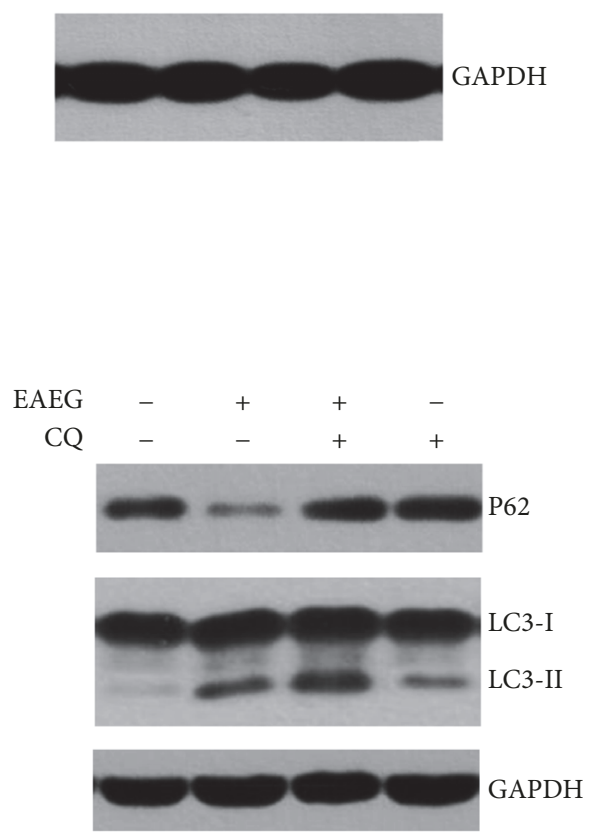

EAEG $(75 \mu \mathrm{g} / \mathrm{ml})$

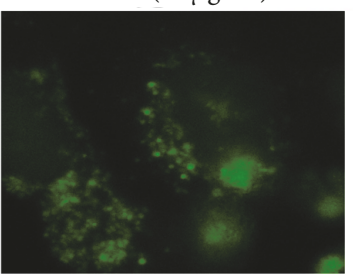

(a)
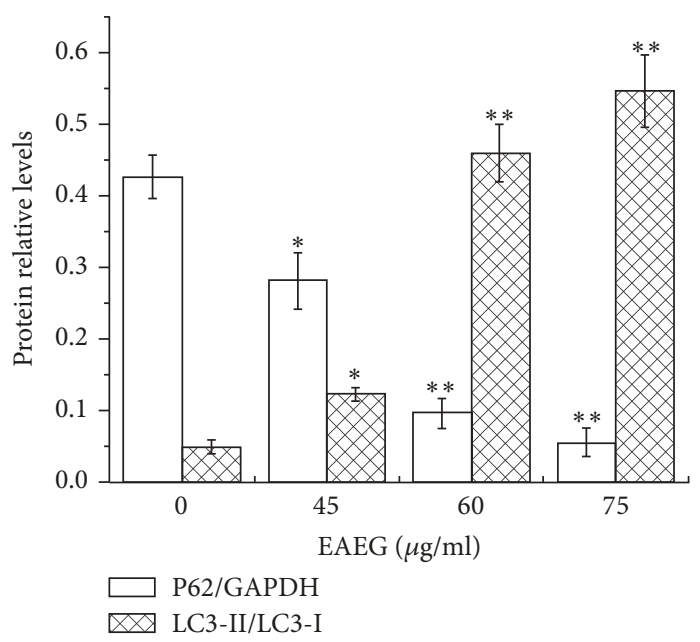

(b)

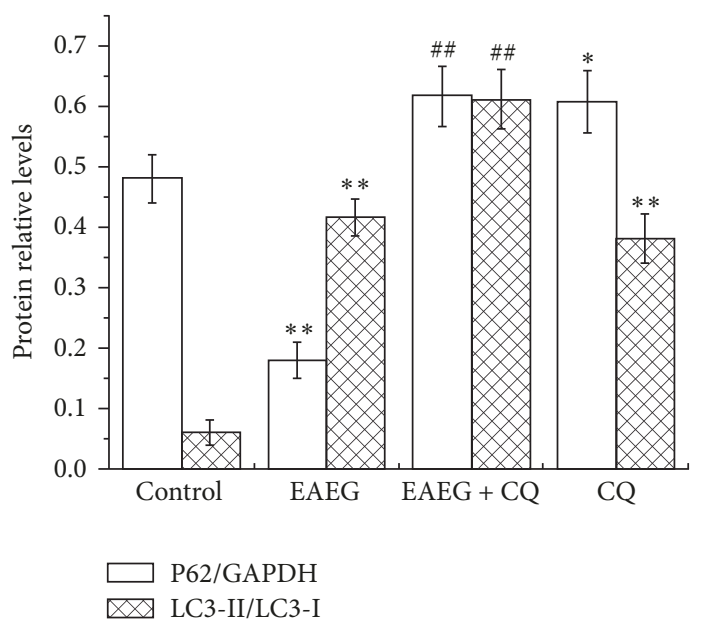

(c)

Figure 3: EAEG induced autophagy in HeLa cells. (a) Analysis of GFP-LC3 puncta formation in GFP-LC3/HeLa cells under fluorescence microscopy. Cells were treated for $24 \mathrm{~h}$ with DMEM only (blank), EAEG solvent (DMSO) as control, different concentrations (45, 60, and $75 \mu \mathrm{g} / \mathrm{ml}$ ) of EAEG, or the positive control trehalose (Tre) (scale bar $=20 \mu \mathrm{m}$.). (b) The expression analysis of the autophagy-related proteins p62 and LC3 by Western blot. HeLa cells were treated for $24 \mathrm{~h}$ with different concentrations $(0,45,60$, and $75 \mu \mathrm{g} / \mathrm{ml})$ of EAEG. (c) The relative protein levels of p62 and LC3-II in HeLa cells treated with $60 \mu \mathrm{g} / \mathrm{ml}$ EAEG with or without CQ (50 mM) for $24 \mathrm{~h}$. GAPDH served as the loading control. The protein relative ratio was calculated using ImageJ. The data were expressed as mean \pm SEM $(n=3)$. ${ }^{*} p<0.05$ and ${ }^{* *} p<0.01$ with respect to the control group. ${ }^{\# \#} p<0.01$ with respect to EAEG treatment group. EAEG: ethyl acetate extract of Gynura formosana Kitam. leaves. 

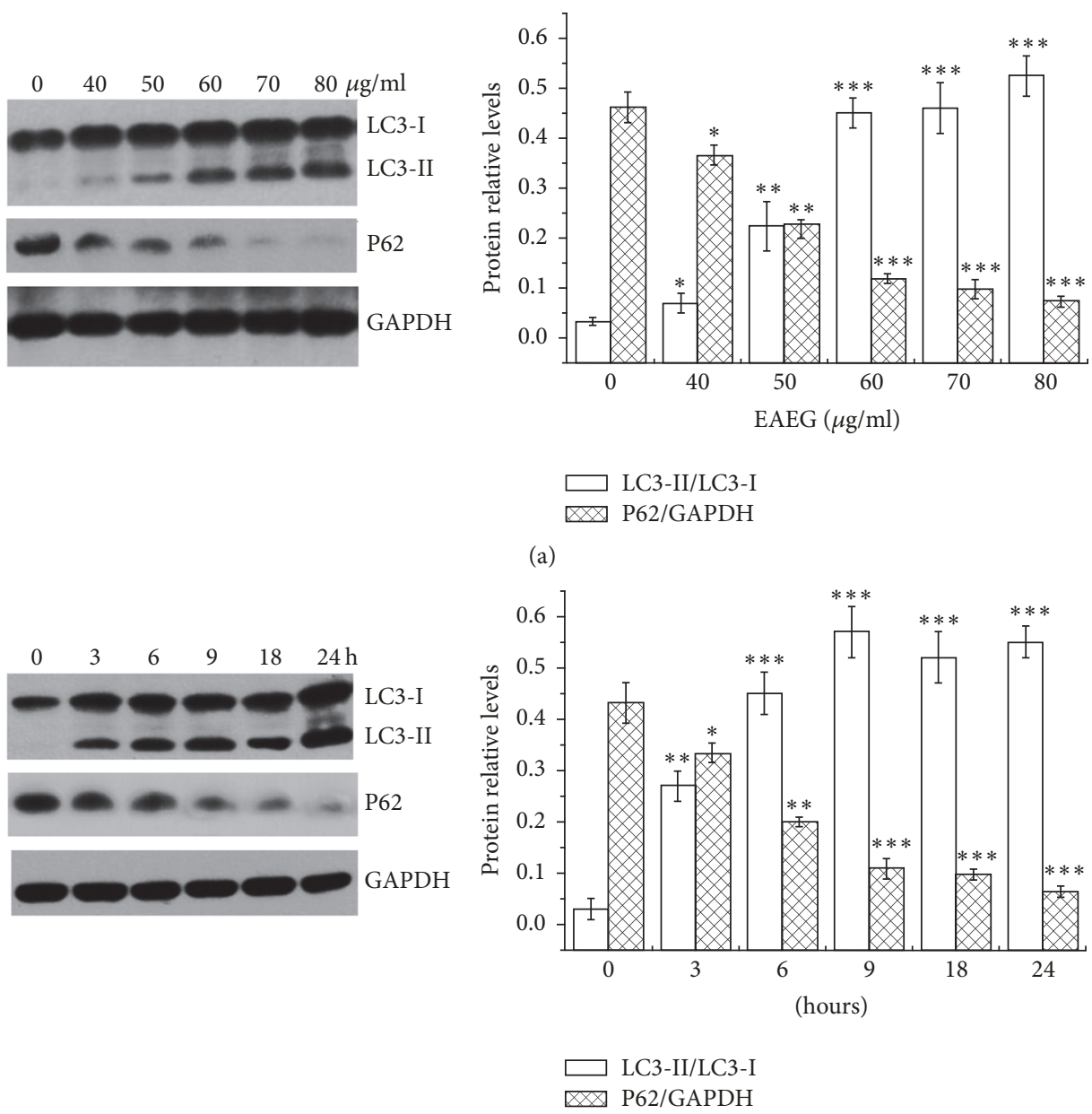

(b)

FIgURE 4: The conversation of LC3-I to LC3-II. Protein level of p62 was measured by Western blot. (a) HeLa cells were treated with EAEG at a concentration of $0,40,50,60,70$, or $80 \mu \mathrm{g} / \mathrm{ml}$ for $24 \mathrm{~h}$. (b) HeLa cells were treated with $60 \mu \mathrm{g} / \mathrm{ml}$ EAEG for $0,3,6,9,18$, or $24 \mathrm{~h}$. GAPDH served as the loading control. The relative protein ratio was calculated using ImageJ. The data were expressed as mean $\pm \operatorname{SEM}(n=3)$. ${ }^{*} p<0.05$, ${ }^{* *} p<0.01$, and ${ }^{* * *} p<0.001$ with respect to the control group. EAEG: ethyl acetate extract of Gynura formosana Kitam. leaves.

apoptosis inhibitor Z-VAD-FMK did not affect the viabilityreducing effect of EAEG (Figures $2(\mathrm{~d})$ and $2(\mathrm{e})$ ). This finding served as a convincing evidence for nonapoptotic cell death in EAEG treated HeLa cells.

Autophagy was considered to be main way to inhibit tumor cells proliferation when cells underwent nonapoptotic cell death $[25,26]$. Increasing evidences had suggested that autophagy could be induced by many natural products in various anticancer therapies. Triterpenoid B-group soyasaponins could induce autophagy in colon cancer cells by inhibition of Akt signaling and enhanced ERK1/2 activity [27]. Polyphenols extracts could induce autophagy, which was advantageous to inhibit neurodegeneration and cancer process [28]. Recent studies demonstrated that Emblica officinalis extracts could also induce autophagy and inhibit human ovarian cancer cell proliferation [29]. These reports supported us to hypothesize that HeLa cells death caused by EAEG could involve autophagy program. Autophagy was a physiologically and pathologically regulated process and played an important role in the maintenance of intracellular homeostasis in every eukaryotic cell [30-32]. It started with inclosing cytoplasmic contents in a vacuole called autophagosome and then autophagosome fused with lysosome to form autolysosome, where substances inside could be degraded and recycled [33]. Autophagy could be initiated by some autophagy-related proteins such as the microtubuleassociated protein LC3, which was a reliable autophagic marker [34]. LC3 was a constitutively expressed protein in mammalian cells and could be processed to form cytosolic LC3-I. During autophagy, LC3-I was recruited to the autophagosome, where LC3-II was generated by fusing LC3-I with phosphatidylethanolamine, and then cellular autophagosome puncta including LC3-II were formed [35]. Our results demonstrated that EAEG upregulated GFP puncta formation (Figure 3(a)) and increased the conversion of LC3-I to LC3-II in HeLa cells (Figure 3(b)), suggesting the recruitment of LC3-II upon EAEG administration. Furthermore, we analyzed the protein level of p62, another autophagic marker [36], to study induction of autophagy. p62 could be trapped by LC3, incorporated into the autophagosome, and then degraded via autophagy. Correspondingly, the protein level of p62 should be decreased in the cells 


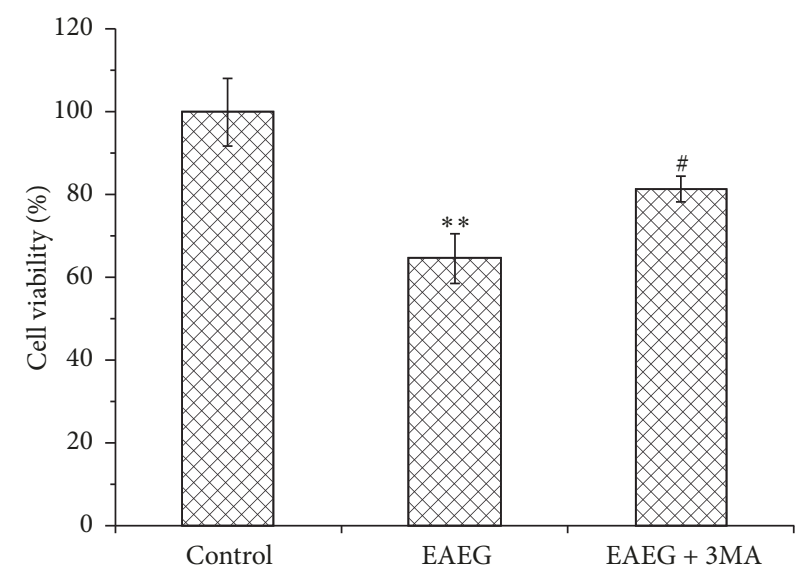

(a)
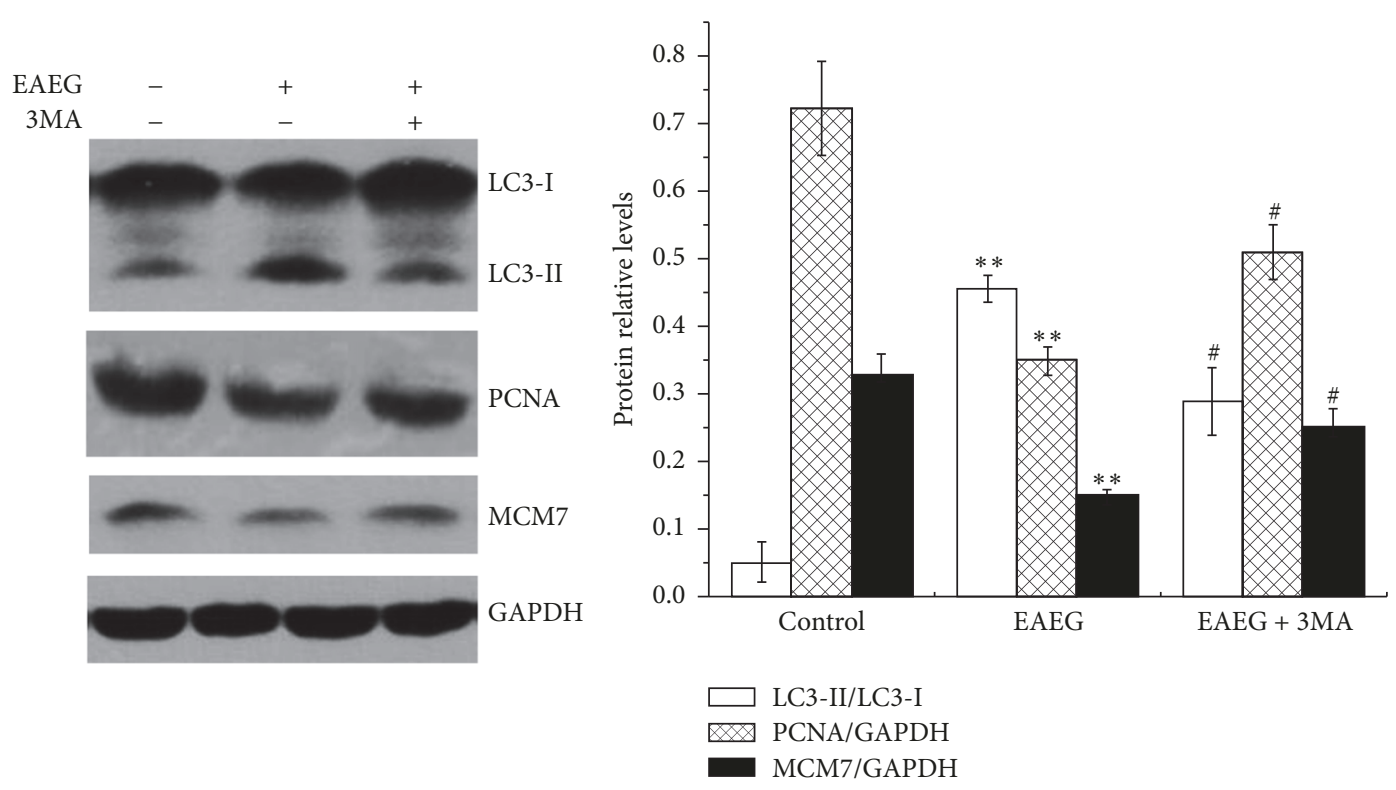

(b)

FIGURE 5: EAEG induced HeLa cells undergoing autophagic cell death. (a) Cell viability of HeLa cells treated with $60 \mu \mathrm{g} / \mathrm{ml}$ EAEG for $24 \mathrm{~h}$ in presence or absence of $5 \mathrm{mM} 3 \mathrm{MA}$. (b) Western blot analysis of autophagy and proliferation proteins. GAPDH served as the loading control. The protein relative ratio was calculated using ImageJ. The data were expressed as mean $\pm \operatorname{SEM}(n=3) .{ }^{* *} p<0.01$ with respect to the control group and ${ }^{\#} p<0.05$ with respect to EAEG treatment group. EAEG: ethyl acetate extract of Gynura formosana Kitam. leaves.

because of autophagy. Our results showed that the protein level of p62 reduced significantly in a dosage-dependent manner after EAEG treatment (Figure 3(b)), indicating an apparent induction of autophagy. However, these results could not explain if EAEG could induce the complete autophagy flux. For instance, calcium phosphate precipitates (CPP) induced both autophagosome synthesis and reduction of autophagy flux due to impaired autophagosome-lysosome fusion [37]. Therefore, it was very necessary to evaluate if the autophagy induced by EAEG was complete autophagy flux including autophagosome formation and autophagosomelysosome fusion. Our results showed that the protein levels of both LC3-II and p62 strongly increased in HeLa cells treated with EAEG together with $\mathrm{CQ}$, compared to cells treated with EAEG alone (Figure 3(c)). These results confirmed that EAEG could induce complete autophagy flux.
To confirm autophagy intensity, we estimated the conversion of LC3-I to LC3-II and protein level of p62. EAEG elicited dose- and time-dependent autophagic induction in HeLa cells through the conversion of LC3-I into LC3-II and decrease of protein level of p62 (Figure 4), strongly suggesting that EAEG had autophagic activity. Additionally, we also demonstrated that 3MA could partially abrogate EAEG induced HeLa cells death, the conversion of LC3-I to LC3-II, and decreasing level of PCNA and MCM7. The presented collective results indicated that EAEG might inhibit HeLa cells proliferation by inducing autophagy.

In summary, our studies indicated that EAEG, a natural plant extract, could be a potentially effective therapeutic agent for treating cervical cancer. Our experimental evidences also supported the traditional use of this plant for the treatment of the deadly disease cancer. The identification of such biological 
compounds in this plant and the mechanism against tumor cells are our research targets in the future.

\section{Conflicts of Interest}

The authors declare that there are no conflicts of interest.

\section{Acknowledgments}

This project was funded by Minxi Public Service Platform for deep processing of Characteristic Agricultural Products (2016LY08), the Natural Science Foundation of Fujian Province (2018J01458), Longyan University (LC2016008), the Training Program of Fujian Excellent Talents in University (MJR201558), and the National Natural Science Foundation of China (81601600).

\section{References}

[1] B. J. Monk, "Invasive Cervical Cancer," in Clinical Gynecologic Oncology, 2012, 1119.

[2] W. Zheng, Z. Liu, W. Zhang, and X. Hu, "miR-31 functions as an oncogene in cervical cancer," Archives of Gynecology and Obstetrics, vol. 292, no. 5, pp. 1083-1089, 2015.

[3] S. E. Waggoner, "Cervical cancer," The Lancet, vol. 361, no. 9376, pp. 2217-2225, 2003.

[4] Y. Chen, H. Wang, W. Lin, and P. Shuai, "ADAR1 overexpression is associated with cervical cancer progression and angiogenesis," Diagnostic Pathology, vol. 12, no. 12, 2017.

[5] S. Sen, R. Chakraborty, C. Sridhar, Y. S. R. Reddy, and B. De, "Free radicals, antioxidants, diseases and phytomedicines: current status and future prospect," International Journal of Pharmaceutical Sciences Review and Research, vol. 3, no. 1, pp. 91-100, 2010.

[6] C. Liu, J.-Z. Liao, and P.-Y. Li, “Traditional Chinese herbal extracts inducing autophagy as a novel approach in therapy of nonalcoholic fatty liver disease," World Journal of Gastroenterology, vol. 23, no. 11, pp. 1964-1973, 2017.

[7] F. S. Reis, R. T. Lima, P. Morales, I. C. F. R. Ferreira, and M. H. Vasconcelos, "Methanolic extract of ganoderma lucidum induces autophagy of AGS human gastric tumor cells," Molecules, vol. 20, no. 10, pp. 17872-17882, 2015.

[8] N. Yu, Y. Xiong, and C. Wang, "Bu-Zhong-Yi-Qi Decoction, the Water Extract of Chinese Traditional Herbal Medicine, Enhances Cisplatin Cytotoxicity in A549/DDP Cells through Induction of Apoptosis and Autophagy," BioMed Research International, vol. 2017, Article ID 3692797, 9 pages, 2017.

[9] J. Ma, C. Guo, Y. Pan, D. Lin, L. Qiu, and L. Wen, "Antioxidant and anti-inflammatory activities of ethyl acetate extract of Gynura formosana (Kitam) leaves," Experimental and Therapeutic Medicine, vol. 14, no. 3, pp. 2303-2309, 2017.

[10] Q. Tian, J. Li, X. Xie et al., "Stereospecific induction of nuclear factor- $\kappa$ B activation by isochamaejasmin," Molecular Pharmacology, vol. 68, no. 6, pp. 1534-1542, 2005.

[11] W.-K. Liu, F. W. K. Cheung, B. P. L. Liu, C. Li, W. Ye, and C.T. Che, "Involvement of p21 and FasL in induction of cell cycle arrest and apoptosis by neochamaejasmin a in human prostate LNCaP cancer cells," Journal of Natural Products, vol. 71, no. 5, pp. 842-846, 2008.
[12] L. Yang, Y. Liu, M. Wang et al., "Celastrus orbiculatus extract triggers apoptosis and autophagy via PI3K/Akt/mTOR inhibition in human colorectal cancer cells," Oncology Letters, vol. 12, no. 5, pp. 3771-3778, 2016.

[13] P.-F. Wei, L. Zhang, S. K. Nethi et al., "Accelerating the clearance of mutant huntingtin protein aggregates through autophagy induction by europium hydroxide nanorods," Biomaterials, vol. 35, no. 3, pp. 899-907, 2014.

[14] J. Yang, Y. Zhou, X. Cheng et al., "Isogambogenic acid induces apoptosis-independent autophagic cell death in human nonsmall-cell lung carcinoma cells," Scientific Reports, vol. 5, pp. 1-9, 2015.

[15] F. Janku, D. J. McConkey, D. S. Hong, and R. Kurzrock, "Autophagy as a target for anticancer therapy," Nature Reviews Clinical Oncology, vol. 8, no. 9, pp. 528-539, 2011.

[16] Z. J. Yang, C. E. Chee, S. Huang, and F. A. Sinicrope, "Autophagy modulation for cancer therapy," Cancer Biology \& Therapy, vol. 11, no. 2, pp. 169-176, 2011.

[17] Y. Lao, G. Wan, Z. Liu et al., "The natural compound oblongifolin C inhibits autophagic flux and enhances antitumor efficacy of nutrient deprivation," Autophagy, vol. 10, no. 5, pp. 736-749, 2014.

[18] H.-M. Ni, A. Bockus, A. L. Wozniak et al., "Dissecting the dynamic turnover of GFP-LC3 in the autolysosome," Autophagy, vol. 7, no. 2, pp. 188-204, 2011.

[19] M. Zhou, L. Yang, M. Shao et al., "Effects of Zearalenone Exposure on the TGF- $\beta 1 / \mathrm{Smad} 3$ Signaling Pathway and the Expression of Proliferation or Apoptosis Related Genes of PostWeaning Gilts," Toxins, vol. 10, no. 2, p. 49, 2018.

[20] D. Xu, Y. Lao, N. Xu et al., "Identification and characterization of anticancer compounds targeting apoptosis and autophagy from Chinese native Garcinia species," Planta Medica, vol. 81, no. 1, pp. 79-89, 2014.

[21] D. R. Green and J. C. Reed, "Mitochondria and apoptosis," Science, vol. 281, no. 5381, pp. 1309-1312, 1998.

[22] C. J. Hawkins and D. L. Vaux, "Analysis of the Role of bcl-2 in Apoptosis," Immunological Reviews, vol. 142, no. 1, pp. 127-139, 1994.

[23] Y. Tsujimoto, "Stress-resistance conferred by high level of bcl$2 \alpha$ protein in human B lymphoblastoid cell," Oncogene, vol. 4, no. 11, pp. 1331-1336, 1989.

[24] D. R. Green, "Apoptotic pathways: paper wraps stone blunts scissors," Cell, vol. 102, no. 1, pp. 1-4, 2000.

[25] S. Tsolmon, J. Han, and H. Isoda, "Inhibition of cell growth by Stellera chamaejasme extract is associated with induction of autophagy and differentiation in chronic leukemia K562 cells," Journal of Bioscience and Bioengineering, vol. 110, no. 2, pp. 262268, 2010.

[26] T. Kanzawa, Y. Kondo, H. Ito, S. Kondo, and I. Germano, "Induction of autophagic cell death in malignant glioma cells by arsenic trioxide," Cancer Research, vol. 63, no. 9, pp. 2103-2108, 2003.

[27] A. A. Ellington, M. A. Berhow, and K. W. Singletary, "Inhibition of Akt signaling and enhanced ERK1/2 activity are involved in induction of macroautophagy by triterpenoid B-group soyasaponins in colon cancer cells," Carcinogenesis, vol. 27, no. 2, pp. 298-306, 2006.

[28] K. Pallauf and G. Rimbach, "Autophagy, polyphenols and healthy ageing," Ageing Research Reviews, vol. 12, no. 1, pp. 237$252,2013$. 
[29] A. De, A. De, C. Papasian et al., "Emblica officinalis Extract Induces Autophagy and Inhibits Human Ovarian Cancer Cell Proliferation, Angiogenesis, Growth of Mouse Xenograft Tumors," PLoS ONE, vol. 8, no. 8, Article ID e72748, 2013.

[30] C. C. Denardin, L. A. M. Martins, M. M. Parisi et al., "Autophagy induced by purple pitanga (Eugenia uniflora L.) extract triggered a cooperative effect on inducing the hepatic stellate cell death," Cell Biology and Toxicology, vol. 33, no. 2, pp. 197-206, 2017.

[31] D. R. Green, L. Galluzzi, and G. Kroemer, "Mitochondria and the autophagy-inflammation-cell death axis in organismal aging," Science, vol. 333, no. 6046, pp. 1109-1112, 2011.

[32] B. Levine, N. Mizushima, and H. W. Virgin, "Autophagy in immunity and inflammation," Nature, vol. 469, no. 7330, pp. 323-335, 2011.

[33] N. Mizushima, B. Levine, A. M. Cuervo, and D. J. Klionsky, "Autophagy fights disease through cellular self-digestion," Nature, vol. 451, no. 7182, pp. 1069-1075, 2008.

[34] V. Thongrakard, R. Titone, C. Follo et al., "Turmeric toxicity in A431 epidermoid cancer cells associates with autophagy degradation of anti-apoptotic and anti-autophagic p53 mutant," Phytotherapy Research, vol. 28, no. 12, pp. 1761-1769, 2014.

[35] A. Kuma, M. Matsui, and N. Mizushima, "LC3, an autophagosome marker, can be incorporated into protein aggregates independent of autophagy: Caution in the interpretation of LC3 localization," Autophagy, vol. 3, no. 4, pp. 323-328, 2007.

[36] M. Komatsu, S. Waguri, M. Koike et al., "Homeostatic levels of p62 control cytoplasmic inclusion body formation in autophagy-deficient mice," Cell, vol. 131, no. 6, pp. 1149-1163, 2007.

[37] S. Sarkar, V. Korolchuk, M. Renna, A. Winslow, and D. C. Rubinsztein, "Methodological considerations for assessing autophagy modulators: A study with calcium phosphate precipitates," Autophagy, vol. 5, no. 3, pp. 307-313, 2009. 


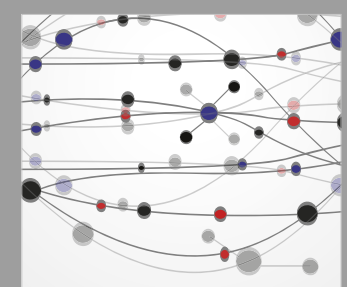

The Scientific World Journal
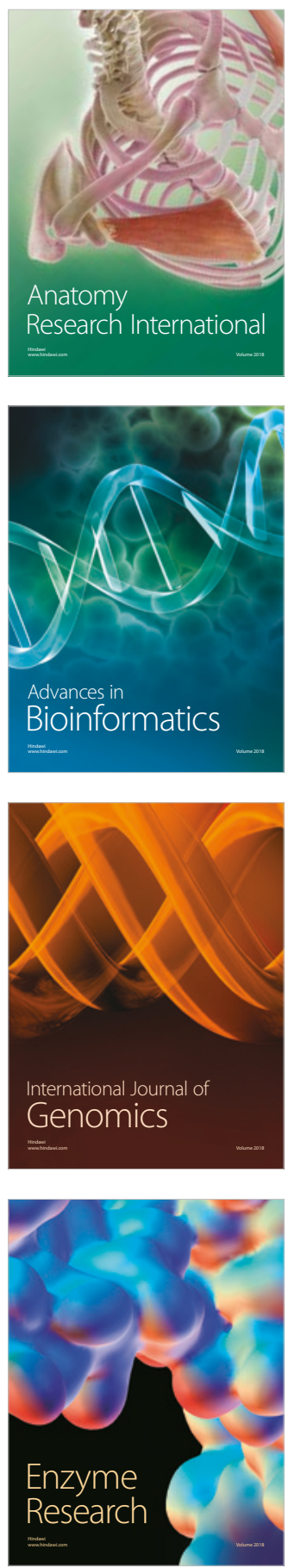
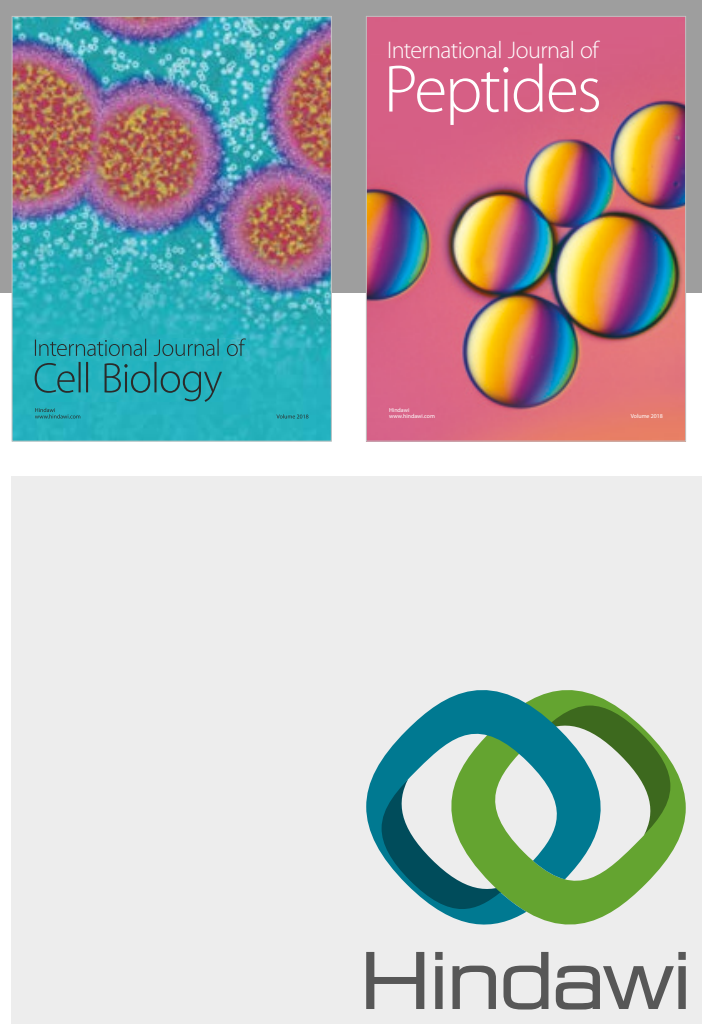

Submit your manuscripts at

www.hindawi.com
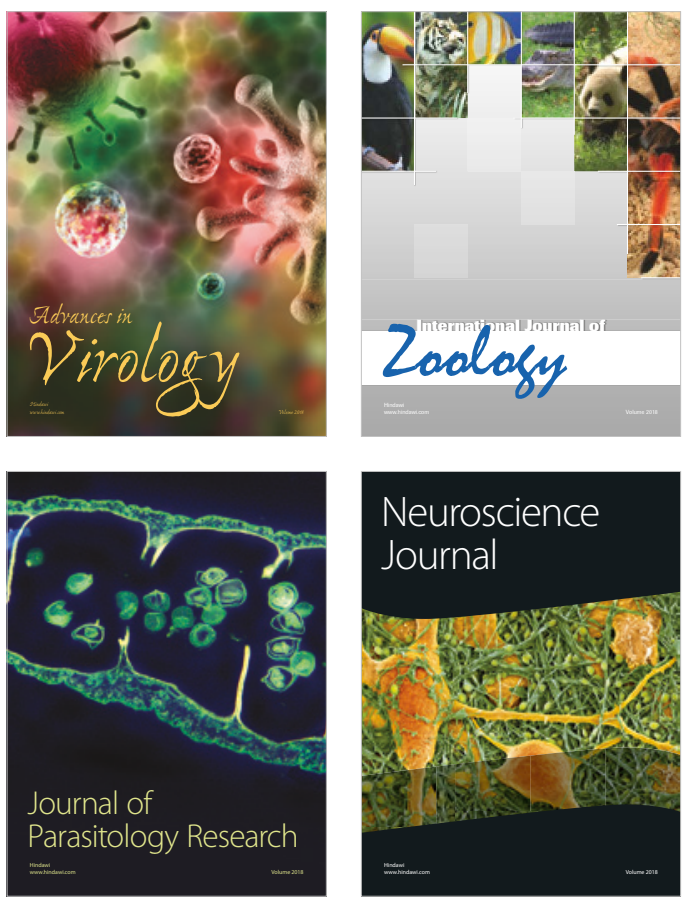
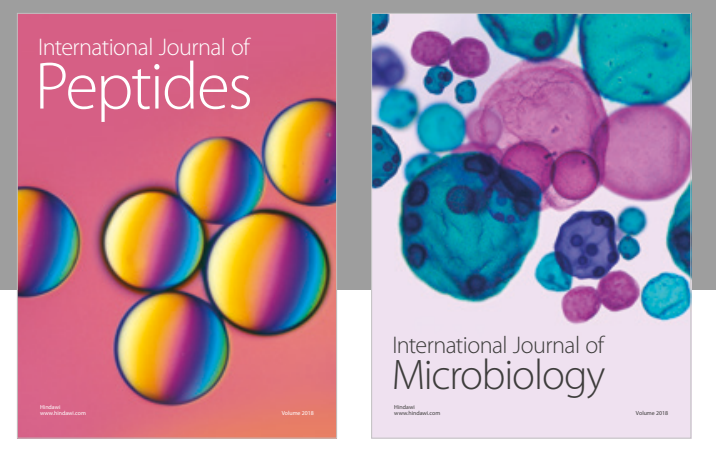

nternational Journal of Microbiology
Journal of
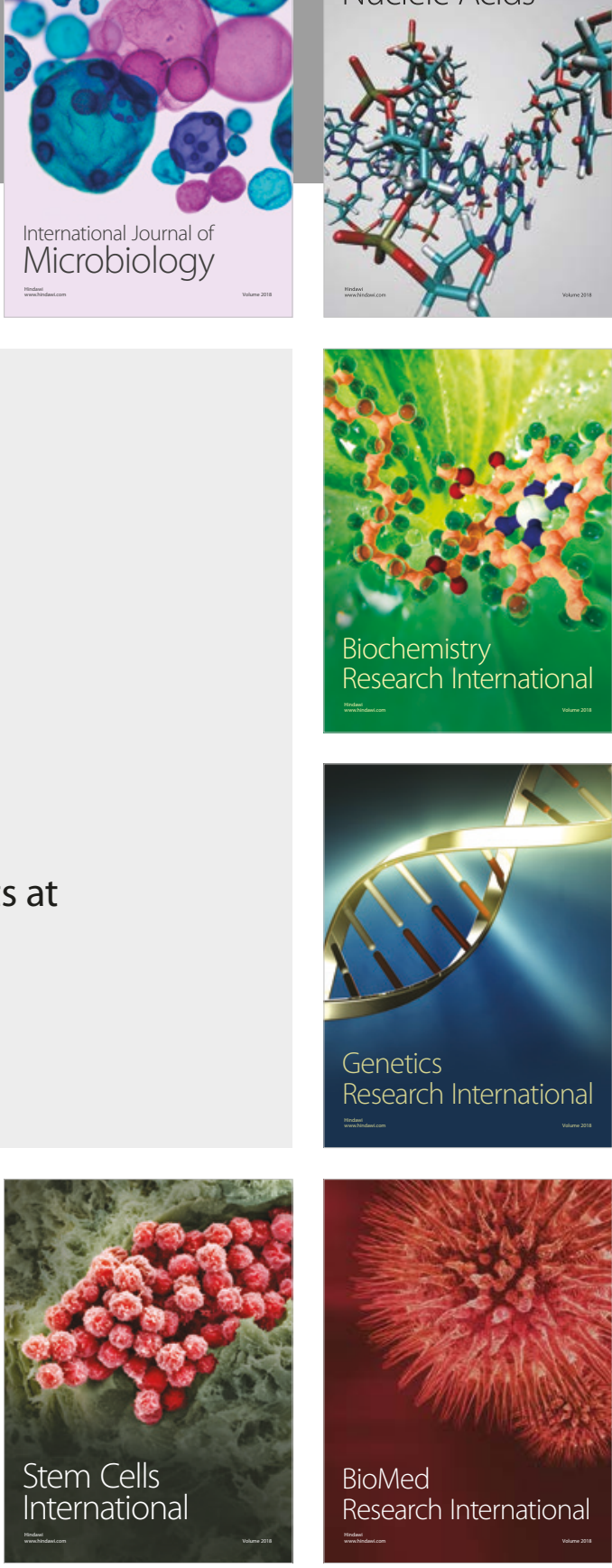
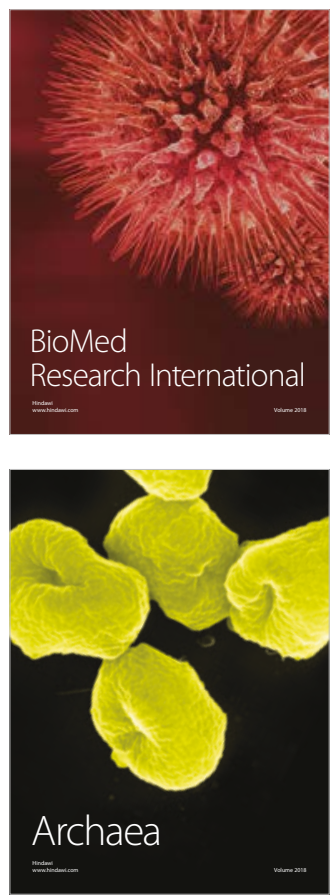